\title{
Article \\ A Novel Axial-Flux Dual-Stator Toothless Permanent Magnet Machine for Flywheel Energy Storage
}

\author{
Yong Zhao ${ }^{1}$, Fangzhou Lu ${ }^{2}$, Changxin Fan ${ }^{3}$ and Jufeng Yang ${ }^{4, *}$ \\ 1 College of Electronic Engineering, Nanjing Xiaozhuang University, Nanjing 211106, China; \\ 2021046@njxzc.edu.cn \\ 2 NARI Technology Co., Ltd., Nanjing 211106, China; lufangzhou@sgepri.sgcc.com.cn \\ 3 Maintenance Branch Company, State Grid Jiangsu Electric Power Co., Ltd., Nanjing 211106, China; \\ fanzx1@js.sgcc.com.cn \\ 4 Automotive Engineering Research Institute, Jiangsu University, Zhenjiang 212013, China \\ * Correspondence: yjf@ujs.edu.cn
}

Citation: Zhao, Y.; Lu, F.; Fan, C.; Yang, J. A Novel Axial-Flux Dual-Stator Toothless Permanent Magnet Machine for Flywheel Energy Storage. Symmetry 2022, 14, 61. https://doi.org/10.3390/sym14010061

Academic Editor: Moo-Yeon Lee

Received: 29 October 2021

Accepted: 6 December 2021

Published: 3 January 2022

Publisher's Note: MDPI stays neutral with regard to jurisdictional claims in published maps and institutional affiliations.

Copyright: (c) 2022 by the authors. Licensee MDPI, Basel, Switzerland. This article is an open access article distributed under the terms and conditions of the Creative Commons Attribution (CC BY) license (https:// creativecommons.org/licenses/by/ $4.0 /)$.

\begin{abstract}
This paper presents an alternative system called the axial-flux dual-stator toothless permanent magnet machine (AFDSTPMM) system for flywheel energy storage. This system lowers self-dissipation by producing less core loss than existing structures; a permanent magnet (PM) array is put forward to enhance the air-gap flux density of the symmetrical air gap on both sides. Moreover, its vertical stability is strengthened through the adoption of an axial-flux machine, so expensive active magnetic bearings can be replaced. The symmetry configuration of the AFDSTPMM system is shown in this paper. Then, several parts of the AFDSTPMM system are optimized thoroughly, including stator windings, number of pole pairs and the PM parameters. Further, the performance of the proposed PM array, including back-EMFs, air-gap flux density, average torque, torque ripple and over-load capacity, are compared with the Halbach PM array and spoke PM array, showing the superiority of proposed configuration. Finally, 3D simulations were made to testify for the 2D analyses.
\end{abstract}

Keywords: flywheel energy storage; toothless permanent magnet (PM) machine; permanent magnet array; optimization and comparison

\section{Introduction}

Permanent magnet (PM) motors (PMMs) with high torque density are being increasingly applied to flywheel energy storage [1-4], due to their great advantages across the distributed power grid [5,6] and electric vehicles [7-9].

However, two shortages still exist in the current PM flywheel energy-storage system (PMFESS). One is these is the electromagnetic loss of the machine, especially the core loss during the holding state $[10,11]$, which has a great negative effect on efficiency and storage time. Thus, making improvements by reducing the iron loss of the machine can further raise the performance of the storage system, on the basis of adopting the vacuum chamber [10]. The other issue is that the introduced longer axial length has an inferior stability to the system [11], owing to the conventional vertical placement of the high-speed PMFESS. Active magnetic bearings are always installed to support the total weight of the rotor, flywheel and shaft, which increases the cost of the system [12].

To improve the above problems, a novel axial-flux dual-stator toothless permanent magnet machine (AFDSTPMM) with symmetry configuration is proposed in this paper. For decreasing the core loss, the stator toothless PM machine, which has little iron loss from the stator yoke, and a lower air-gap flux density, is proposed. A new PM array is raised to enhance the bilateral stator field. To optimize stability in the vertical direction, the dual-stator axial-flux machine is used. This can generate vertical force to support the rotor, by arranging double windings and controlling the stator currents. Therefore, the active 
magnetic bearings are no longer needed, and can be replaced by passive magnetic bearings. Consequently, the aforementioned two shortcomings can be ameliorated. In addition, the proposed machine has other advantages, such as an improved overload capacity due to a larger magnetic reluctance. Additionally, it also has a small weight, high efficiency, good dynamic performance and a low self-dissipation rate.

\section{Construction of the AFDSTPMM}

Figure 1 shows the cross-section of the AFDSTPMM system. Figure 1a displays the 2D cross section of the AFDSTPMM system, whose main components are listed in Table 1 . The center of the system is a high-speed rotating rotor, which consists of a flywheel and PM array connected by rotor cores, as shown in Figure $1 \mathrm{~b}$. Both sides of the rotor are arranged symmetrically with a set of stator winding, as in Figure 1c,d. Each winding is fixed to the stator back iron through non-magnetic material, jointly fastened on the vacuum chamber. A set of axial bearings and radial bearings are arranged on both sides of the shaft. All of the axial bearings and radial bearings are passive magnetic bearings because of their smaller size, cheaper price.

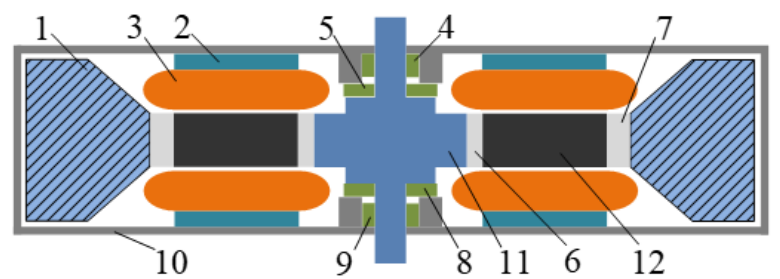

(a)

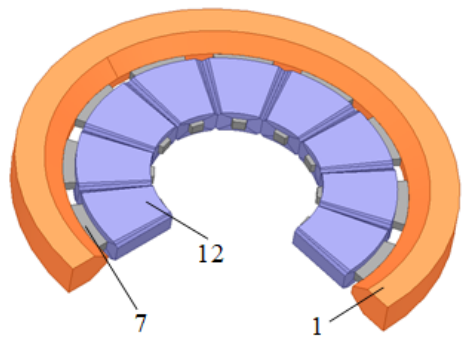

(b)

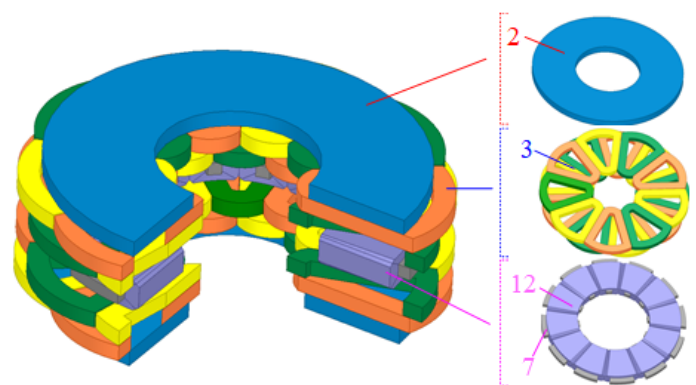

(c)

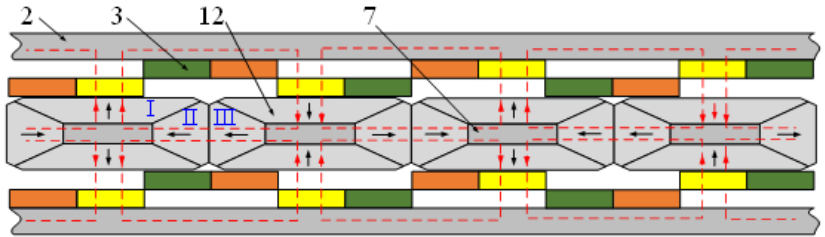

(d)

Figure 1. AFDSTPMM system. (a) 2D cross-section of AFDSTPMM system. (b) 3D cross-section of rotor. (c) 3D cross-section of AFDSTPMM. (d) 2D equivalent cross-section of proposed machine. 
Table 1. Components of AFDSTPMM.

\begin{tabular}{cc}
\hline Part Number & Part Name \\
\hline 1 & Flywheel \\
2 & Stator back iron \\
3 & Stator windings \\
4,9 & Radial bearings \\
5,8 & Axial bearings \\
6,7 & Rotor core \\
10 & Vacuum chamber \\
11 & Shaft \\
12 & PM array \\
\hline
\end{tabular}

Figure $1 \mathrm{c}$ is the $3 \mathrm{D}$ cross-section of AFDSTPMM. The 2D equivalent electromagnetic structure of this machine is displayed in Figure 1d. It can be seen that each pole of the proposed PM array consists of four PMs, arranged around the central rotor core. The polarity of the PMs at the same position of the adjacent poles are all opposite, whereas the polarity of adjacent PMs in same pole (e.g., PM I and II) and adjacent poles (e.g., PM II and III) are both opposite, causing them to attract to each other. This is also easier to install than classical structures $[13,14]$. Reinforced frames are distributed between adjacent blocks of PMs. Further, there are only two magnetizing directions for PMs. The rotor cores can act not only as magnetic conduction circuit, but also as a supporting structure of the rotor.

The actual air-gap length of the machine can be considered as the vertical distance between the PMs and the back iron of the stator, as shown in Figure 1d. This can be designed to be large, due to the existence of the proposed PM array and back irons. Consequently, the distance between the stator coil and the rotor surface can be designed to be longer, under the same actual air gap length. In other words, the machine allows the existence of a larger air-gap length between the stators and the rotors on both sides of the rotor. Hence, the suspension range becomes bigger, and the suspension control of the rotor will be simpler. Some specific simulated parameters are provided in Table 2.

Table 2. Parameters of the AFDSTPMM.

\begin{tabular}{ccc}
\hline Parameters & Unit & Value \\
\hline Stator outer diameters & $\mathrm{mm}$ & 160 \\
Rotor outer diameters & $\mathrm{mm}$ & 140 \\
Stator thickness & $\mathrm{mm}$ & 10 \\
Layers of the stator & - & 2 \\
Stator inner diameters & $\mathrm{mm}$ & 50 \\
Rotor inner diameters & $\mathrm{mm}$ & 70 \\
Rotor thickness & $\mathrm{mm}$ & 14 \\
\hline
\end{tabular}

With this system, as shown Figure 1a, the axial force is provided by the axial magnetic bearing when rotor is static, and provided by the comprehensive axial magnetic tension during suspension. Thus, the bearings can adopt passive magnetic bearings, and the rotor axial position is adjusted by axial magnetic pulling force in working time.

\section{Optimization of the AFDSTPMM}

\subsection{Arrangement of Windings}

To rectify the difficulty of arranging the windings from the inner diameter of the axial flux motors, the double-layer non-overlapping concentrated winding (DLNOCW) is proposed for this machine, as shown in Figure 2a. The whole windings are divided into two layers, namely the blue solid wire and the red dotted wire. Each layer is arranged tightly. With the same total winding axial length, each coil of the DLNOCW compensates for the decrease of axial length, derived from winding layering, by increasing its width. 
The average torque will be at its maximum when $\theta_{c_{-a v e}}$ is near 150 electric degrees, as shown in Figure $2 b$, under the premise of $\theta_{m}$ being at a 240 degree electric angle [15].

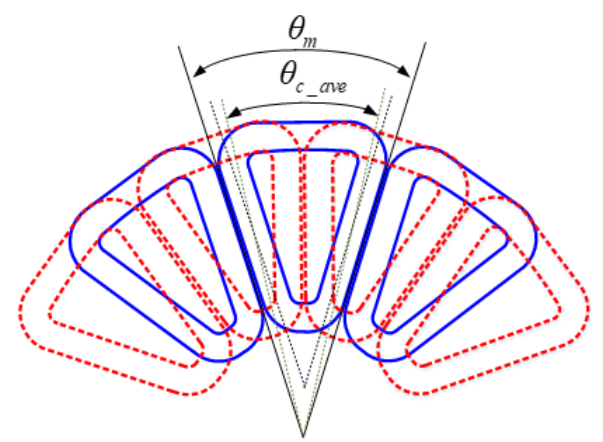

(a)

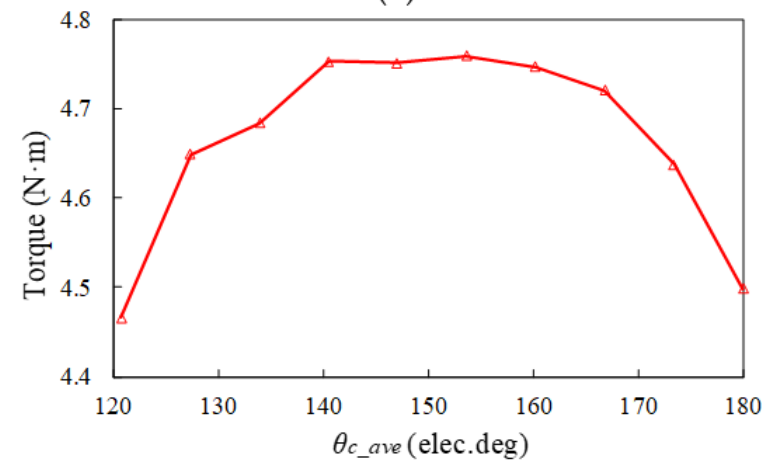

(b)

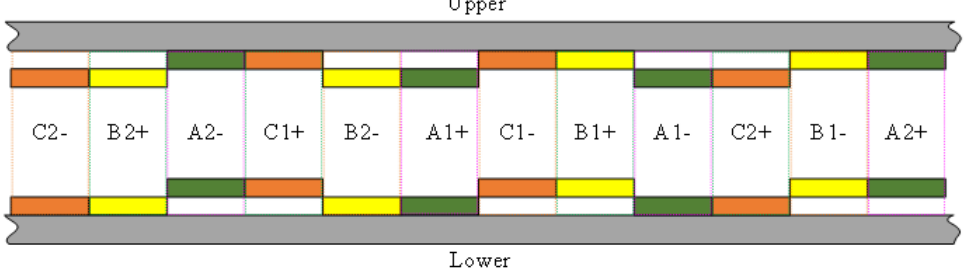

(c)

Figure 2. Arrangement of the AFDSTPMM. (a) Coil arrangement; (b) torque and $\theta_{\mathcal{C}_{-} a v e}$. (c) winding arrangement.

Figure 2c shows the transposition of the windings, which is aimed at reducing the circulation of current between parallel wires. Each coil consists of four parts, which are arranged on double stators. For the same side, the coils of same phase are arranged symmetrically, near or far from the PMs. For instance, in the upper winding, the coils A1, $\mathrm{B} 2$ and $\mathrm{C} 2$ are close to PMs, whereas A2, B1 and C1 are far from the PM (A contains A1 and A2). For the different sides of same coil, their positions are also different. For example, the upper part of coil A1 is close to PMs, whereas its lower part is far from PMs. Hence, the same back-EMF amplitude of different phases can be obtained, and will not be affected by a great variation in air-gap flux density.

\subsection{Number of Pole Pairs}

In order to realize the design of DLNOCW, the pole-pairs number $(p)$ of PMs must be even. Figure 3 presents the relationship between torque and $p$. It can be drawn that the torque of the motor is largest when $p$ is 6 , which is used in the following simulations. It should be identified that the rotational inertia of the flywheel in the proposed motor is larger due to the great radius; therefore, the speed of the flywheel can be reduced correspondingly, while the $p$ can also be increased as a result. 


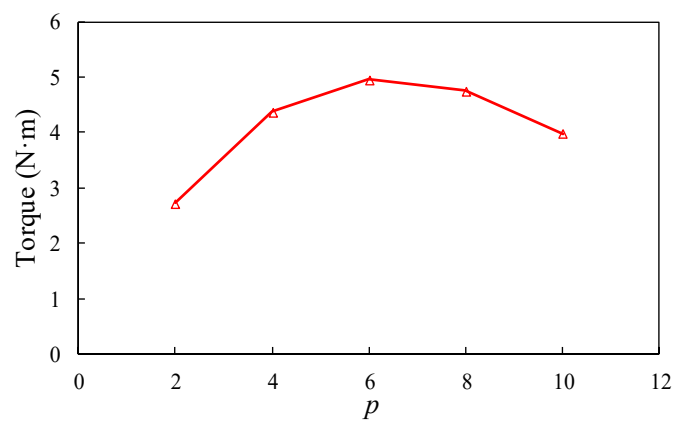

Figure 3. Relationship between Torque and $p$.

\subsection{Parameters of PMs}

In this section, the parameters of the proposed PM array are optimized. The cross section of the PM array is demonstrated in Figure $4 \mathrm{a} . h_{v p}$ and $h_{h p}$ are the thickness of the axial and circumferential PMs, respectively, $h_{p t}$ and $l_{p t}$ are the axial height and circumferential length of the PM array, respectively, and $h_{p t}$ and $l_{p t}$ remain invariant during improvement.

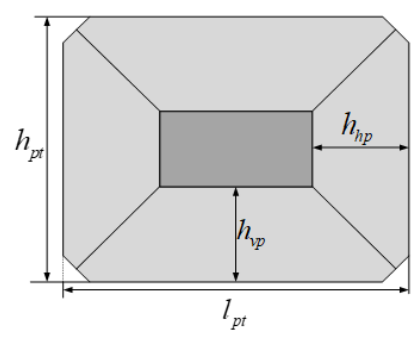

(a)

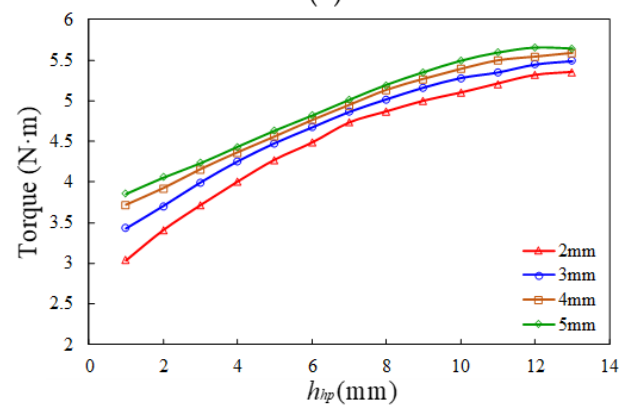

(b)

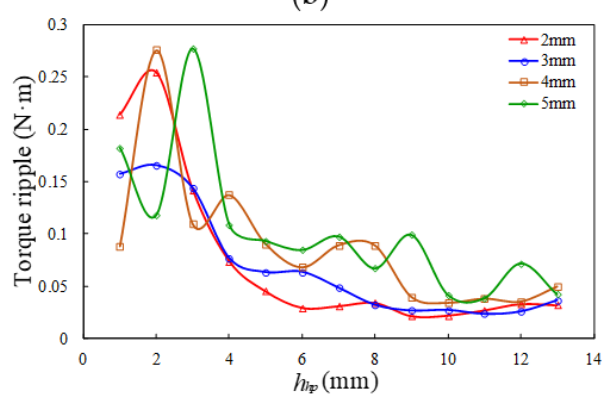

(c)

Figure 4. Torque property versus $h_{h p}$ under different $h_{v p}$. (a) PM array; (b) average torque; (c) torque ripple.

Figure $4 \mathrm{~b}, \mathrm{c}$ show the average torque and torque ripple versus $h_{h p}$, when $h_{v p}$ varies from $2 \mathrm{~mm}$ to $5 \mathrm{~mm}$, separately. Figure $4 \mathrm{~b}$ shows that the average torque increases with the growth of $h_{h p}$ and $h_{v p}$. Figure 4c shows torque ripple when $h_{v p}$ is between $2 \mathrm{~mm}$ to $5 \mathrm{~mm}$, and that the torque ripple decreases when $h_{v p}$ gets smaller. In addition, the torque ripple is the smallest when $h_{h p}$ changes between $9 \mathrm{~mm}$ to $11 \mathrm{~mm}$. As a consequence, for the bigger 
torque and the smaller torque ripple, the next comparisons are conducted with $h_{v p}$ and $h_{h p}$ at $2 \mathrm{~mm}$ and $9 \mathrm{~mm}$, respectively, taking the difficulty of machining into consideration.

\section{Comparison with Conventional PM Arrays}

The performance of the AFDSTPMM is compared with two conventional PM arrays, namely the Halbach array and the Spoke PM array, which are shown in Figure 5. All of these have been improved under the premise of same rotor's size, stator's size and $p$.

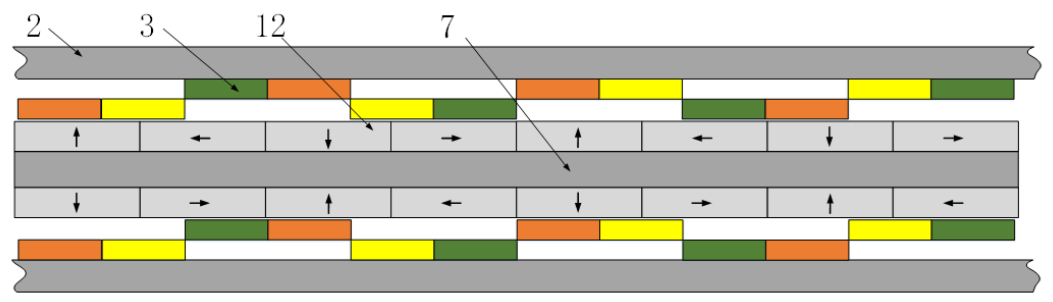

(a)

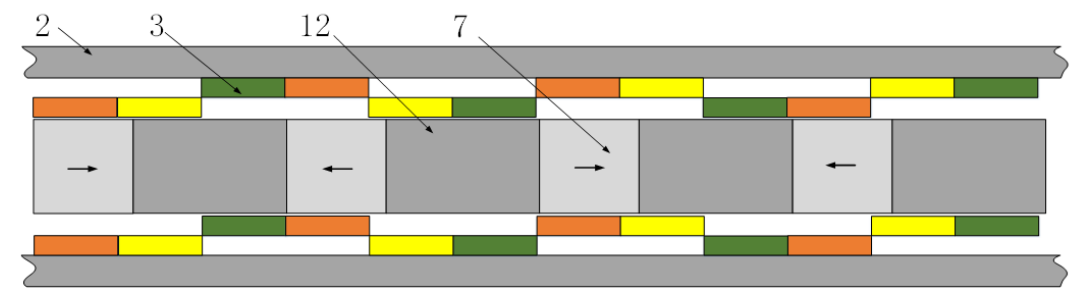

(b)

Figure 5. Two conventional PM arrays. (a) Halbach array; (b) Spoke PM array.

Figure 6a shows the back-EMFs, in which the amplitude of the proposed AFDSTPMM is at its maximum, and those of the other two arrays are close. Figure $6 \mathrm{~b}$ displays the open-circuit air-gap flux density waveforms, and each one has two situations, namely waveforms near PM and away from PM. It can be seen that the waveforms, farther away from PM, have lower amplitude but more sinusoidal, and the comparison results are similar to that of back-EMFs. Figure 6c shows the average torque follow the order proposed $>$ Halbach > Spoke. Further, the torque ripple of proposed array is smallest and that of Halbach is highest. The numerical results of back-EMFs and torques are shown in Table 3. In addition, Figure $6 \mathrm{~d}$ offers torque under different overload situation, from which it can be discovered that the overload ability of proposed PM array is best. And some specific torques under different currents which prove the overload abilities are shown in Table 4.

Table 3. Comparisons of back-EMFs and torque.

\begin{tabular}{ccccc}
\hline Parameters & Unit & Halbach & Spoke & Proposed \\
\hline Peak of phase back-EMFs & $\mathrm{V}$ & 4.51 & 4.46 & 5 \\
Average torque & $\mathrm{N} \cdot \mathrm{m}$ & 4.85 & 4.76 & 4.98 \\
\hline
\end{tabular}

Table 4. Comparison of overload ability.

\begin{tabular}{ccccc}
\hline Overload times & Unit & Halbach & Spoke & Proposed \\
\hline 2 & $\mathrm{~N} \cdot \mathrm{m}$ & 9.81 & 9.51 & 9.98 \\
5 & $\mathrm{~N} \cdot \mathrm{m}$ & 23.32 & 23.75 & 24.92 \\
7 & $\mathrm{~N} \cdot \mathrm{m}$ & 32.31 & 33.22 & 34.88 \\
10 & $\mathrm{~N} \cdot \mathrm{m}$ & 45.8 & 47.38 & 49.79 \\
\hline
\end{tabular}




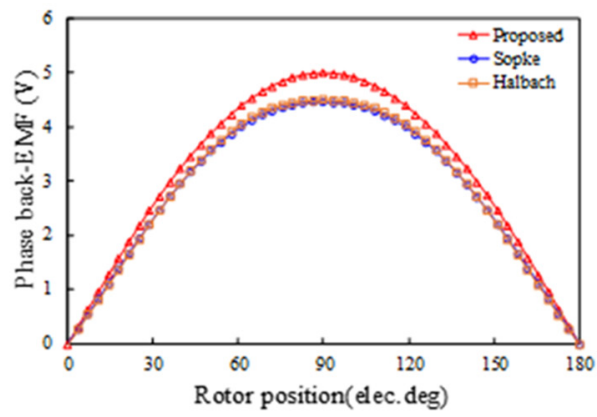

(a)

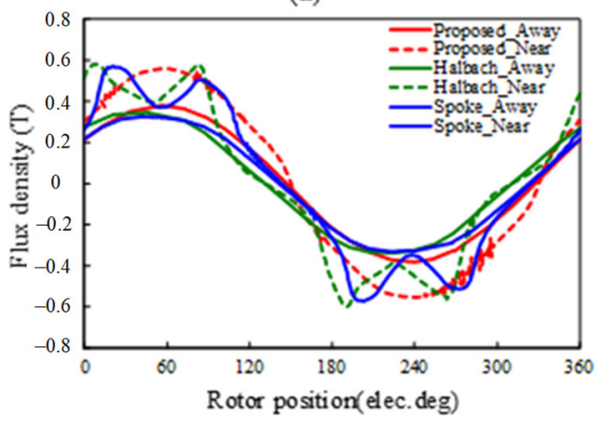

(b)

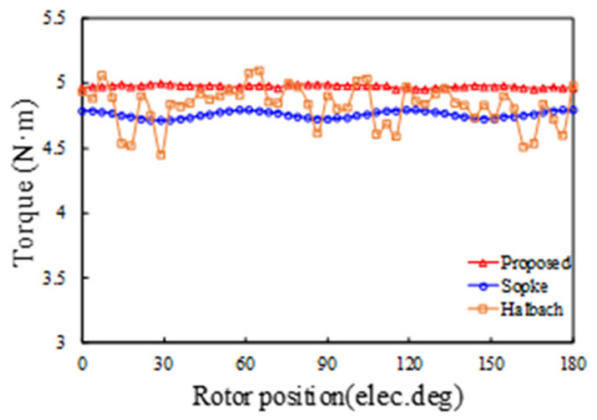

(c)

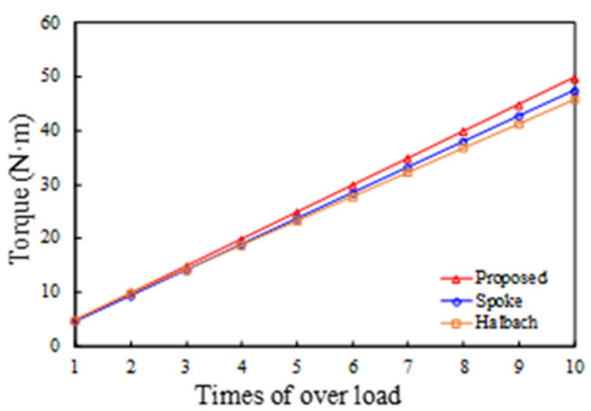

(d)

Figure 6. Performance comparison. (a) Back-EMF; (b) air-gap flux density; (c) rated torque; (d) torque versus current.

Several 3D simulations have been conducted to verify the results of the 2D simulations. Figure 7a shows the back-EMFs of 2D and 3D, in which the amplitude of 2D and is $4.98 \mathrm{~V}$ and $4.85 \mathrm{~V}$, respectively, a $2.6 \%$ difference. The average torques of $2 \mathrm{D}$ and $3 \mathrm{D}$ are $5 \mathrm{~N} \cdot \mathrm{m}$ and $4.85 \mathrm{~N} \cdot \mathrm{m}$, a $3 \%$ difference. The specific values are listed in Table 5 . The error range of the back-EMF and torque meets the requirements, showing that the $2 \mathrm{D}$ analysis results are effective. 


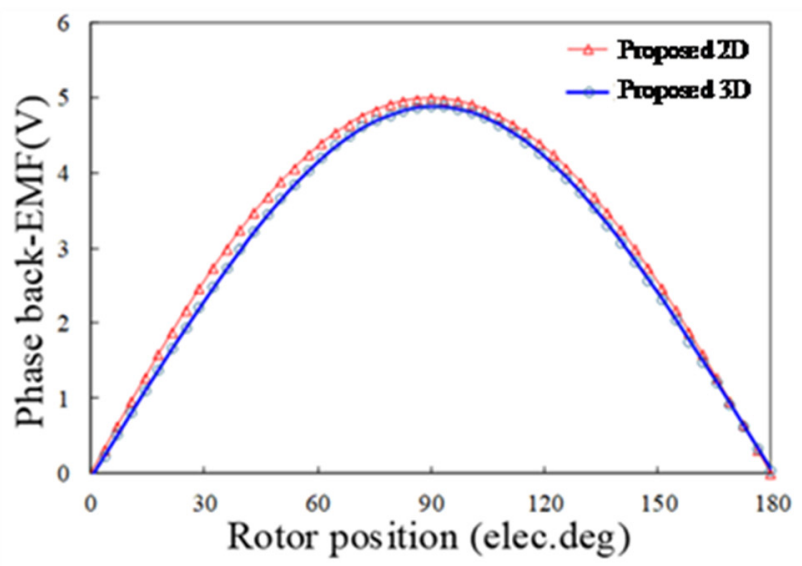

(a)

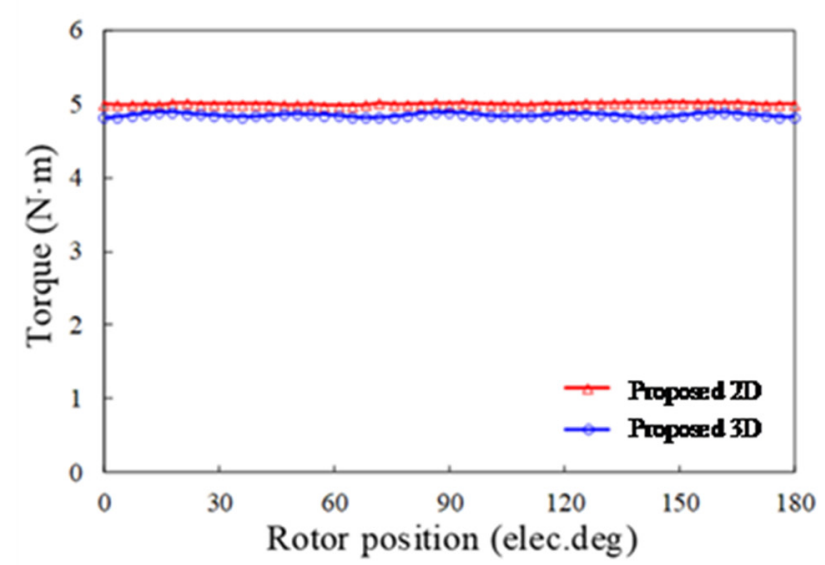

(b)

Figure 7. Comparisons between 2D and 3D simulation. (a) Back-EMFs; (b) average torque.

Table 5. Comparisons of 2D and 3D simulation.

\begin{tabular}{cccc}
\hline Parameters & Unit & 2D & 3D \\
\hline Peak of phase back-EMFs & $\mathrm{V}$ & 4.98 & 4.85 \\
Average torque & $\mathrm{N} \cdot \mathrm{m}$ & 5 & 4.85 \\
\hline
\end{tabular}

\section{Conclusions}

A symmetrical axial-flux dual-stator toothless permanent magnet machine (AFDSTPMM) has been proposed in this paper. To improve efficiency, the toothless structure has been adopted. Moreover, for increasing air-gap flux density, a novel PM array has been presented. In addition, the axial-flux machine has been combined to enhance vertical stability and reduce cost. The structure of the AFDSTPMM has been introduced in detail. Then, the optimization of the winding arrangement, pole-pair number and PMs was detailed. The performance of the proposed PM array was compared with two conventional arrays, indicating that the proposed machine has great advantages in multiple aspects. Finally, 3D simulations were carried out, verifying the result of the $2 \mathrm{D}$ simulations.

Author Contributions: Conceptualization, Y.Z.; software, Y.Z.; validation, Y.Z.; investigation, F.L., C.F. and J.Y.; writing—original draft preparation, Y.Z. and J.Y.; writing—review and editing Y.Z., and J.Y. All authors have read and agreed to the published version of the manuscript.

Funding: This research was funded by the China Postdoctoral Science Foundation (2020M671356), and the Natural Science Foundation of Jiangsu Province (BK20210773).

Institutional Review Board Statement: Not applicable. 
Informed Consent Statement: Not applicable.

Data Availability Statement: Not applicable.

Conflicts of Interest: The authors declare no conflict of interest.

\section{References}

1. Swider, D.J. Compressed air energy storage in an electricity system with significant wind power generation. IEEE Trans. Energy Convers. 2007, 22, 95-102. [CrossRef]

2. Faraji, F.; Majazi, A.; Al-Haddad, K. A comprehensive review of flywheel energy storage system technology. Renew. Sustain. Energy Rev. 2017, 67, 477-490.

3. Nieto, A.; Vita, V.; Ekonomou, L.; Mastorakis, N.E. Economic analysis of energy storage system integration with a grid connected intermittent power plant, for power quality purposes. WSEAS Trans. Power Syst. 2016, 11, 65-71.

4. Nieto, A.; Vita, V.; Maris, T.I. Power quality improvement in power grids with the integration of energy storage systems. Int. J. Eng. Res. Technol. 2016, 5, 438-443.

5. Saleh, A.; Awad, A.; Ghanem, W. Modeling, control, and simulation of a new topology of flywheel energy storage systems in microgrids. IEEE Access 2019, 7, 160363-160376. [CrossRef]

6. Bianchini, C.; Torreggiani, A.; David, D.; Bellini, A. Design of motor/generator for flywheel batteries. IEEE Trans. Ind. Electron. 2021, 68, 9675-9684. [CrossRef]

7. Tang, X.; Hu, X.; Yang, W.; Yu, H. Novel torsional vibration modeling and assessment of a power-split hybrid electric vehicle equipped with a dual-mass flywheel. IEEE Trans. Veh. Technol. 2017, 67, 1990-2000. [CrossRef]

8. Ershad, N.F.; Mehrjardi, R.T.; Ehsani, M. High-performance 4wd electric powertrain with flywheel kinetic energy recovery. IEEE Trans. Power Electron. 2020, 36, 772-784. [CrossRef]

9. Ershad, N.F.; Mehrjardi, R.T.; Ehsani, M. Efficient flywheel-based all-wheel-drive electric powertrain. IEEE Trans. Ind. Electron. 2021, 68, 5661-5671. [CrossRef]

10. Han, Y.; Ren, Z.; Tong, Y. General design method of flywheel rotor for energy storage system. Energy Procedia 2012, 16, 359-364. [CrossRef]

11. Arslan, M.A. Flywheel geometry design for improved energy storage using finite element analysis. Mater. Des. 2008, 29, 514-518. [CrossRef]

12. Nguyen, T.D.; Tseng, K.-J.; Zhang, S.; Nguyen, H.T. A novel axial flux permanent-magnet machine for flywheel energy storage system: Design and analysis. IEEE Trans. Ind. Electron. 2011, 58, 3784-3794. [CrossRef]

13. Zhang, B.; Doppelbauer, M. Iron losses calculation of an axial flux machine based on three-dimensional FEA results corresponding to one-sixth electrical period. IEEE Trans. Energy Convers. 2017, 32, 1023-1030. [CrossRef]

14. Kamper, M.J.; Wang, R.-J.; Rossouw, F.G. Analysis and performance of axial flux permanent-magnet machine with air-cored nonoverlapping concentrated stator windings. IEEE Trans. Ind. Appl. 2008, 44, 1495-1504. [CrossRef]

15. Xia, B.; Shen, J.-X.; Luk, P.C.-K.; Fei, W. Comparative study of air-cored axial-flux permanent-magnet machines with different stator winding configurations. IEEE Trans. Ind. Electron. 2014, 62, 846-856. [CrossRef] 